\title{
Physico-technical approach to design of composites from mineral and polymer technogenic resources
}

\author{
Gotfrīds Noviks \\ Rezeknes Augstskola, Faculty of Engineering
}

\begin{abstract}
Artificial composite materials are currently being produced in large quantities, they are diverse and they are widely used in the economy. There have been extensive theoretical and experimental studies of different types of components, developed the calculation methods of composites production with predefined properties.

At the same time industry produces a lot of mineral and polymer waste, which are practically technogenic resources, but their use is currently at quite low levels. The paper examines the possibilities to use technogenic resources- mineral (such as ash and clay) and organic (polymers -PET containers) for producing qualitative composite materials. For this purpose theoretical analysis and calculations of the physical properties of components and process parameters that determine the operating characteristics of the composite material were carried out.

Composite-forming process efficiency determinative parameters were analysed: adhesion, the specific surface energy, specific free surface, adsorption capacity and the degree of dispersion of the particles.

The role of external factors in processing of composite were examined - temperature, concentration of components.

The characteristics of prepared samples of composites showed the possibility to use these waste for the development of qualitative products for different purposes.
\end{abstract}

Keywords: adhesion, composites, mineral waste, PET waste.

\section{INTRODUCTION}

A very significant part of the solid waste produced in the world is inorganic - mineral residues and waste. In literature a term ,inorganic waste" often is used to determine not only really inorganic matter, but synthetic organic substances which do not originate in natural processes and are non-biodegradable also (e.g., plastic products) [1]. To avoid such misunderstanding in our study we used the term "mineral waste", i.e., all those materials, which are inorganic according to classical chemistry - the remnants of the construction and repair, debris and work off a building material, mineral extraction by-products, glass and glass-use industrial waste, ceramic waste, burning remnants, including ash, air and gas purification precipitated dust $[2,3]$.

Eiropean Union statistics [4,5] shows that only during 5 recent years in 28 countries of the EU waste volumes increased by 10 million tons. (from 2505 million tons in year 2010 to 2515 million tons in year 2014), of which mineral solid waste constitutes 1780 million tons.

In general, in the EU as a whole is recycled only about $10 \div 12 \%$ of the waste. Latvia in 2014 produced more than 2.3 million tons of waste including mineral waste 0.68 million tons.

Despite the fact that this waste is essentially valuable technogenic mineral resource, most of it is not currently fully utilized. One reason for this - there is no developed mineral waste recycling process optimization methodology. Most of the research is dedicated to the natural organic waste managment.

At the same time mineral waste processing facilities, equipment and technology very differs from the organic waste treatment processes.

As was shown in our previous studies [2] the analysis of mineral waste recycling possibility must be carried out on the basis of their original features and compatibility with planned production quality. It prioritizes most perspective waste materials research directions. If the mineral waste basic properties meet the standarts for planned production, they can be directly or after minimal processing included in the production or manufacture of the reuse cycle.

However, such technogenic waste are quite a few (glass, metal scrap). Most of the waste have lost their original characteristics and the immediate return to the production process is technically cumbersome and uneconomical. So necessity to deeper processing of waste to produce a new product with a higher value to compensate the costs associated with recycling is

ISSN 1691-5402 
actual task. Since most mineral waste are not biodegradable and can not be used as a fuel for thermal energy, the processing must be based on physical fields - mechanical treatment, thermal treatment, electromagnetic fields, thermo chemical processes. According to mineral waste composition and desired products may be selected one of two courses of their processing: disintegration or integration[2]. Disintegration means division raw materials in the respective components for the purpose to release of components for further use or distribute unfit (dangerous) components with a view to enhancing the quality of the residual components.

Disintegration technologies are quite widely used to waste water processing, rare elements extraction of coal ash, etc.

Integration is a composite formation process - in this case, a key factor is the optimal composition and structure of component finding (creation of compound -blend) and determination of necessary physical fields and modes of production, which can result in a final product designed in a previous forecast physical parameters. Solid waste recycling in this direction may prove to be effective. Components with different initial properties and their concentrations combination makes it possible to obtain materials with new properties.

Composite behaviour and its properties are not only determined by the properties and volume fractions of the components, but also appeares certain new features due to the joint action of different components and external agent- so called synergetic effects.

For example, the Korea Advanced Institute of Science and Technology (KAIST) [6] developed a composite of only 4.10-5\% graphene inserted in metal. As a result the composite strength increased of more than 100 times. To get the desired properties of composite materials need to select the appropriate composite composition and treatment regime.

In fact, almost all naturally occurring objects are composites. Artificial most widely known composite is a concrete.

At present was created many modifications of concrete using as additional components liquid polymers, organic binders: polymer concrete, lightweight concrete, etc. Artificial composite materials (fiber-reinforced polymers, metal matrix composites, composite ceramic etc.) are currently produced in large quantities, they are diverse and they are widely used in the economy $[7,23,25]$. There have been extensive theoretical and experimental studies of different types of components, developed the methods of calculation predefined properties of composites [8].

Normally composite consists of two components matrices and reinforcement material. Depending on the nature and structure of components may be various composites formed. Accordingly raw materials are specially selected and treated. For example, the reinforcement (filling) material may be discrete (fiber) or continuous (threads, fabrics, netting), but matrix polymers, oligomers, various binders.

The determining factors of composite properties can be combined into three groups:

The first group includes internal physical and chemical properties of composite-forming material:

- The physical properties of raw materials: mechanical, thermal, electromagnetic.

Minerals can be completely described by the physical parameters of a complex consisting of 12 basic indicators: density $\delta$, porosity $\mathrm{P}$, compressive $\sigma \mathrm{c}$ and tensile $\sigma$ t strength, Young's modulus E, Poisson's ratio $\eta$, specific thermal conductivity $\lambda$, specific heat $\mathrm{c}$, thermal expansion coefficient $\beta$, specific electrical resistivity $\rho$, dielectric permeability $\varepsilon$, specific permeability $\mu$ [9]

- Physical-chemical and chemical properties - phase transition temperature Tph and thermal effects, physico-chemical transformation enthalpy $\Delta \mathrm{H}$, physico-chemical activity G, solubility S.

- Surface properties- specific surface energy $\gamma$, adhesion work wa adsorption parameters $\mathrm{F}$, diffusion coefficients D.

The second group include external parameters of the components changeable in the technological process:

- Physical geometrical parameters included in the composite structure components - the size of particles $d$, the shape, specific free surface $\mathrm{S}$, mutual positions and orientations.

- Concentration of components $\mathrm{C}$.

The third group includes the exposure factors on the basis of which is designed the composite production technology:

- Physical fields and physical-chemical processes.

- Operation modes: pressure, temperature, time, gradients, parameters of electromagnetic field, etc.

Since the creation of the composite material is carried out in order to obtain new materials with predetermined properties need to be predictable properties calculations. Composite theory develops a variety calculation methods of composite properties.

Percolation theory developed by Broadbent and Hammersley in 1957 currently is quite widely used approach to substance and energy transfer processes in the description of disordered systems (consisting mainly of two components) [10,11]. Theory determines the probability of the formation of clusters and predicts the composite flow properties (thermal conductivity, electrical conductivity, diffusion, dielectric and magnetic permeability, flexibility parameters). The decisive factor in the theory of percolation is critical threshold - critical probability $\mathrm{pc}-$ in the case of two components pc is equal to minimum filling component's (substrate) concentration $\mathrm{xc}$ at which the composite properties 
changes drastically - e.g., dielectrics turns into a conductor[12,13,14,15].

According to this theory, when one component (X1) property A value is a1 and volume concentration is $\mathrm{x} 1$ and the second component (X2) has the value a2 of the same property (and the concentration $\times 2=1$ $\mathrm{x} 1$ ), the value of composite property ac can be calculated depending on the other components' threshold concentration xcr (or critical probability pcr) from the formulas:

$$
\mathrm{ac}=\mathrm{a}_{1}\left(\mathrm{x}_{\mathrm{cr}}-\mathrm{x}_{2}\right)^{-\mathrm{q}}
$$

if $\mathrm{x}_{2}<\mathrm{x}_{\mathrm{cr}}$

$$
\mathrm{a}_{\mathrm{c}}=\mathrm{a}_{2}\left(\mathrm{a}_{1} / \mathrm{a}_{2}\right)^{\mathrm{s}}
$$

if $\mathrm{x}_{2}=\mathrm{x}_{\mathrm{cr}}$.

$$
\mathrm{ac}=\mathrm{a} 2(\mathrm{x} 2-\mathrm{xcr}) \mathrm{t}
$$

if $\mathrm{x}_{2}>\mathrm{x}_{\mathrm{cr}}$.

Here $\mathrm{q}, \mathrm{s}, \mathrm{t}$ - critical indices.

The relationship between the critical indices can be described by formula [13].

$$
\mathrm{q}=\mathrm{t}(1 / \mathrm{s}-1)
$$

In the two-phase system critical probability is between about $1 / 3$ and $2 / 3, \mathrm{~s}=0.5, \mathrm{q}=\mathrm{t}=1.3$.

In this theory a key parameter - the critical probability pc is quite variable. For most cases pc can not be calculated exactly, and is dependent on the components of the structure and their distribution (particle size, shape, orientation). In addition, there is no well-defined what it means to move from one position to the second, changes in characteristics occur even though at different speeds, but gradually.

For calculation outside the critical area can be used effective medium theory [16,17], which is based on the assumption that the two components are immersed in an effective homogeneous environment, the characteristic of which aef coincides with the composite real physical property a.

Effective medium theory pertains to analytical or theoretical modeling that describes the macroscopic properties of composite materials and is developed from averaging the multiple values of the constituents that directly make up the composite material.

$[(\mathrm{a} 2-\mathrm{aef})(\mathrm{x} 2) /(\mathrm{a} 2+2 \mathrm{aef})]+[(\mathrm{a} 1-\mathrm{aef})(\mathrm{x} 1) /(\mathrm{a} 1+2 \mathrm{aef})]=0$

Calculating statistical mixture properties ac containing only the two components with concentrations V1 and V2 and values of properties a1, a2 accordingly, quite widely is used V.I. Odelevsky equation [18]

$$
\mathrm{ac}=\mathrm{B}+\sqrt{\mathrm{B} 2}+\mathrm{a} 1 \cdot \mathrm{a} 2
$$

where: $\mathrm{B}=[(3 \mathrm{~V} 2-1)+\mathrm{a} 2(3 \mathrm{~V} 1-1) \mathrm{a} 1]$
Our analysis has shown [11] that the composite scalar (additives) physical parameters can be calculated by the formula arithmetic average weighted. Flow intensity parameters when the composite material is laminated and each layer consists of one component parallel to the layers may be most accurately calculated after the arithmetic average weighted also.

$$
\mathrm{x} / /=\mathrm{x} \mathrm{xiVi}
$$

but perpendicular to the layers - after the harmonic average weighted.

$$
1 / \mathrm{xF}=\Sigma(\mathrm{Vi} / \mathrm{xi})
$$

The parameters which characterize the resistance of the flow, are calculated the contrary: the parallel layers - at the harmonic average weighed and perpendicular - by the arithmetic average weighted.

In other cases, the entire range of physical values change within the area limited by these two curves depending on the placement of components.

Statistically homogeneous environment where the content ratio of components in the mixture is close to $50 / 50$ best fits the actual values of the parameters calculated using the weighted average logarithmic formula

$$
\lg \mathrm{x}=\Sigma \mathrm{Vi} \lg \mathrm{xi}
$$

When one of the components by volume becomes predominant changes the structure type - its component, which occupies a larger volume begins to play a decisive role and as a result properties of composite are nearer to equations 6 or 7 . On the basis of investigation of natural composite materials-rocks [19] we obtained the regularities and nomograms, which can be also used in artificial composite properties forecasting (Fig.1).

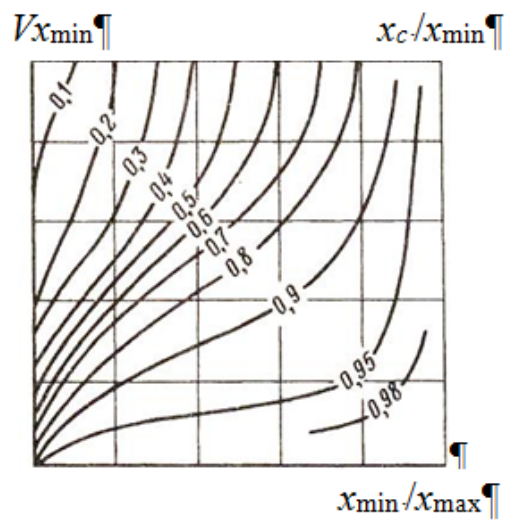

Fig.1. Nomogram for calculation physical property $x_{\mathrm{c}}$ of compounds consisting of two components : $\mathrm{V}_{\mathrm{xmin}}$ - volume of component what physical parameter is $x_{\min } ; x_{\max }$ - physical parameter of second component (larger).

Established that in the case of two statistically distributed components the relationship between the 
concentrations of the components and properties may be approximated by a curve consisting of 6 different segments. But, as already mentioned, the developed calculation scheme for composite physical parameters is feasible only for flow characteristics- matter and energy transfer properties.

Calculation structurally sensitive tensor physical parameters of the composites is much more uncertain.

In all cases, the composite material is a monolithic whole, bringing together the components within them. So, the key here is the new links which are formed between the components, their physical nature and properties. This means that the mechanical links between the components calculations must take into account not only aditives, but synergetic effects produced in the contact areas. In forecasting these ties major role have the interfacial layers properties between the matrix and the confinement (Fig.2).

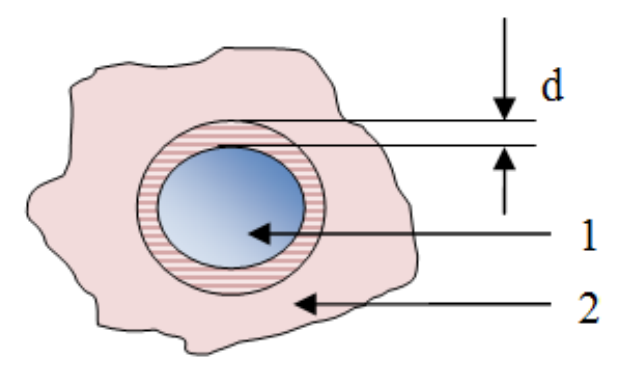

Fig.2. Interfacial layer d between inclusion 1 and matrix 2 . $\mathrm{d}=0.01 \div 5 \mu \mathrm{m}$.

Studies [20] showed that the interfacial layer thickness is from 0.01 to $5 \mu \mathrm{m}$. This layer properties determine the specific components of the surface energy, adhesion and adsorption characteristics. Adhesion determines composite strength and crack formation and propagation in the processes [21]. Currently, there are several theories of adhesion [22,23]: mechanical theory of adhesion, adsorption theory, diffusion theory, electrostatic diffusion theory. They are based on the various interaction effects, such as:

- Lifshitz-van der Waals interactions,

- molecular interactions,

- adsorption,

- mechanical interlock,

- chemical bonding.

Molecular theory in addition to adhesion effect takes into account the physical chemical interaction between polymer and substrate, associated with catalysis, specific polymer transformations and polymer structure characteristics.

If there is no adhesion, any inclusion in matrix reduces the strength of the matrix due to stress concentration formed in the area around the inclusion, which leads to the destruction of the material.
Adhesion work $w_{\mathrm{a}}$ depends on components and the contact area specific surface energy, respectively, $\gamma_{1}$, $\gamma_{2}, \gamma_{1-2}$ according to the equation:

$$
\mathrm{w}_{\mathrm{a}}=\gamma_{1}+\gamma_{2}-\gamma_{1-2} \text {. }
$$

According to F.M.Fawkes [24,28] contact surface energy can be calculated by the following formula:

$$
\gamma_{1-2}=\gamma_{1}+\gamma_{2}-2\left(\gamma_{1} \cdot \gamma_{2}\right)^{0.5}
$$

A.W.Neumann [24,29] offers more precise equation:

$$
\left.\gamma_{1-2}=\left(\gamma_{1}{ }^{0,5}-\gamma_{2}^{0,5}\right) / 1-0.015\left(\gamma_{1} \cdot \gamma_{2}\right)^{0.5}\right]
$$

Adhesion strength may be equaled to adhesion only if the connection have not defects and rupture occurs at low speed.

\section{MATERIALS AND METHODS}

This study examines the possibilities to recycle in useful product mineral waste- ash and clay combining them in composite with polymer waste-PET bottles. It is known that production of PET bottles in the world is increasing. [5,26,27]. Given into account that this waste is not biodegradable, its stock rises steadily.

In USA 32 million tons of plastic waste were generated in 2012, representing $12.7 \%$ of total municipal solid waste, among them almost 14 million tons of plastics as containers and packaging. And only $9 \%$ of the total plastic waste generated in 2012 was recovered for recycling [30].

Our previous studies showed that there is an ash disposal problem also and it even does not solve using the renewable organic energy resources. For example, Finland produce annually 6.105 tons of ash, Sweden 8.105 tons, USA- 3.106 tons, China 2.106 tons. [31]

The aim was to find out in principle the possibility of creating a monolithic composite containing the matrix-forming fraction - thermoplastic polymer as a binder adhesive and substrate - a mineral filler components - ash or clay. Ash and especially wood ash characteristics were investigated during last 3 years [31,32].

Clay samples for experiments were taken from the largest Latvian Kupravas clay deposit.

The second component - used polyethylene terephthalate (PET) bottles.

PET bottles were shredded in slivers with size of 3$5 \mathrm{~mm}$, clay were dried and ground, ash were sieved to separate from unburned coarse coal particles.

Two types of clay were used - white and brown.

Ash samples were taken from household furnaces. Physical parameters of initial components shown in table 1.

Granulometric curves of mineral compounds are presented in fig.3.

Samples were set up as a two-component system, respectively:

- Clay + PET, 
- Ash + PET.

PET concentration varied from 20 to 80 mass percent.

The components were mixed and with mixture were filled aluminum foil cups of $38 \mathrm{~mm}$ in diameter and $10 \mathrm{~mm}$ in height. Cups were placed in a muffle furnace and heated to temperatures in the range 230 0C $-3100 \mathrm{C}$, exposed at these temperatures for 10 minutes. During this time the melted material was mixed. Then it was cooled and investigated.

Measured properties of the resulting composite: density, hardness, conductivity wettability (table2).

Visual sample analysis results are displayed in Fig. (4-7).

TABLE 1.

PROPERTIES OF COMPONENTS [31,33,34,35,36]

\begin{tabular}{|c|c|c|c|c|}
\hline $\mathrm{N}$ & Property & PET & Clay & Ash \\
\hline 1. & Density, $\mathrm{g} / \mathrm{cm}^{3}$ & 1.38 & $2.6-2.8$ & $1.74-1.87$ \\
\hline 2. & $\begin{array}{l}\text { Specific area } \\
\text { surface, } \mathrm{m}^{2} / \mathrm{g}\end{array}$ & - & $\begin{array}{l}41-83 \\
61-346 \\
222 \\
18-30\end{array}$ & $2.2-2.9$ \\
\hline 3. & $\begin{array}{l}\text { Specific surface } \\
\text { energy, } \mathrm{mJ} / \mathrm{m}^{2}\end{array}$ & $\begin{array}{l}44 \\
\text { (av) }\end{array}$ & $\begin{array}{l}60.2 \\
74.4 ; 75 \\
222\end{array}$ & 20 (av.) \\
\hline 4. & $\begin{array}{l}\text { Adsorption, } \\
\mathrm{mg} / \mathrm{g}\end{array}$ & $\begin{array}{l}0.05- \\
0.8\end{array}$ & $\begin{array}{l}15(27-48 \% \\
\text { oil) }\end{array}$ & $\begin{array}{l}1.2 \\
\text { (metylen } \\
\text { blue) }\end{array}$ \\
\hline 5. & $\begin{array}{l}\text { Particle size } \\
\text { (av.) }\end{array}$ & - & $5.10^{-3}$ & $3.10^{-1}$ \\
\hline 6. & $\begin{array}{l}\text { Melting } \\
\text { temperature, }{ }^{0} \mathrm{C}\end{array}$ & $\begin{array}{l}200- \\
260\end{array}$ & 1200 & 1230 \\
\hline 7. & $\begin{array}{l}\text { Young Module, } \\
\text { GPa }\end{array}$ & $\begin{array}{l}2,7- \\
3.45\end{array}$ & 7.2 & - \\
\hline 8. & $\begin{array}{l}\text { Tensile } \\
\text { strength, MPa }\end{array}$ & $\begin{array}{l}47-90 \\
(79.3)\end{array}$ & 1.2 & - \\
\hline
\end{tabular}

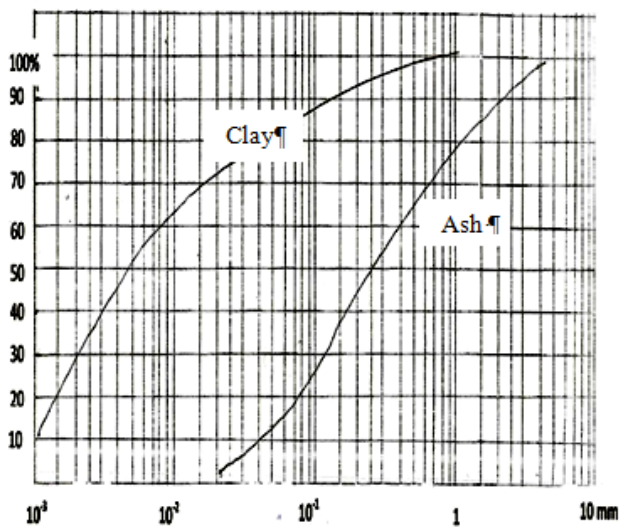

Fig.3. Granulometric curves of clay and ash

\section{RESULTS AND DISCUSSION}

Experiments show that, despite the fact that PET melting temperature according to the technical data is $260^{\circ} \mathrm{C}$, at this temperature polymer is incapable to coat evenly all substrate particles, due to the high viscosity of PET. Only at temperatures of $300{ }^{0} \mathrm{C}-$ $320{ }^{\circ} \mathrm{C}$ all particles overlap with the polymer film, and thanks to the adhesion forms the monolithic structure.

Polyethylene terephthalate (Polymer Thermoplastic resin) specific surface energy is in the range (32-80) $\mathrm{mJ} / \mathrm{m}^{2}$ according to literature data [35], the average 44 $\mathrm{mJ} / \mathrm{m}^{2}$.

Clay specific surface energy depends on the mineral composition and can vary between 75 and $169.5 \mathrm{~mJ} / \mathrm{m}^{2}$ [36] and even $175 \mathrm{~mJ} / \mathrm{m}^{2}$ for kaolinite [37].

For the previous calculations may take $150 \mathrm{~mJ} / \mathrm{m}^{2}$.

Using this data specific surface energy according to Fawkes formula (10) for composite "Clay+PET” will be:

$$
\gamma_{c-p}=150+44-2(150 \cdot 44)^{0.5}=31.5 \mathrm{~mJ} / \mathrm{m}^{2}
$$

and adhesion work $w_{a}=150+44-31,5=162.5 \mathrm{~mJ} / \mathrm{m}^{2}$. Wood ash specific surface energy to our previous studies may be accepted on average $20 \mathrm{~mJ} / \mathrm{m}^{2}$ and calculation using formula (10) for composite ,Ash + PET" contact specific surface energy $\gamma_{a-p}$ gives 4.7 $\mathrm{mJ} / \mathrm{m}^{2}$ and adhesion work $w_{a}=20+4.67=59.33$ $\mathrm{mJ} / \mathrm{m}^{2}$.

In accordance to Neumann equation (11) the contact surface energy can be calculated for composite „Clay + PET” as

$\gamma_{c-p}=\left(150^{0.5}-44^{0.5}\right) /\left[1-0.015(150 \cdot 44)^{0.5}\right]=25.4 \mathrm{~mJ} / \mathrm{m}^{2}$ and wa $=168.8 \mathrm{~mJ} / \mathrm{m}^{2}$.

Composite „Ash + PET” accordingly $\gamma_{a-p}=3.9 \mathrm{~mJ} / \mathrm{m}^{2}$ and $\mathrm{w}_{\mathrm{a}}=60.1 \mathrm{~mJ} / \mathrm{m}^{2}$.

As we see, the results of the calculations using formulas (10) and (11) are pretty close, and in both cases it shows that PET contact surface energy with clay is more than 6 times and adhesion work is around 2.7 times larger than the contact with ashes.

The experimental results also show that in order to achieve optimal mechanical parameters the proportions „Ash:PET” and „Clay:PET” in composites must be different.

In either case if PET content is less than $30 \%$ (mass) the components are poorly connected together and as a result we have mechanically weak, porous structure of composite (Fig 4.).

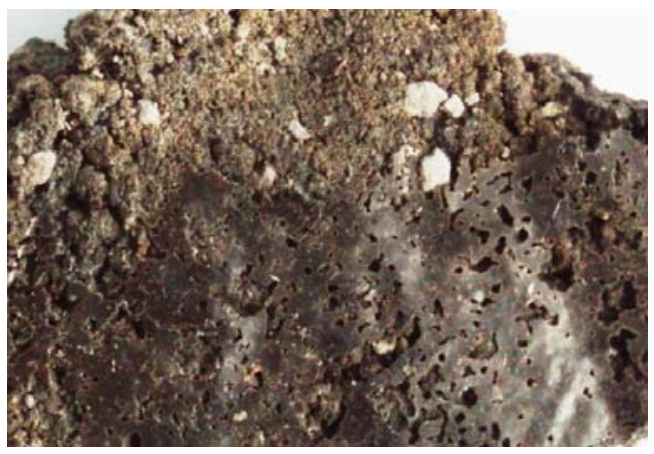

Fig . 4. Composite from mixture „Clay + PET”. PET content 30\% (mass) 
In composite" Clay + PET" starting from 50\% PET content formed homogenous monolythic structure with high mechanical properties: hardness on the Mohs scale - 6-7, the average bulk density $1.79 \mathrm{~g} / \mathrm{cm}^{3}$ (white clay) and $1.77 \mathrm{~g} / \mathrm{cm}^{3}$ (brown clay). (Fig.5). In composite "Ash + PET" if there are $50 \%$ of ash, the most part of them $(32 \%$ ash) remains free and are not bonded with the polymer. Sintered part is fragile and its density is only $1.44 \mathrm{~g} / \mathrm{cm}^{3}$, which indicates the high porosity of the composite (Fig.6).

a)

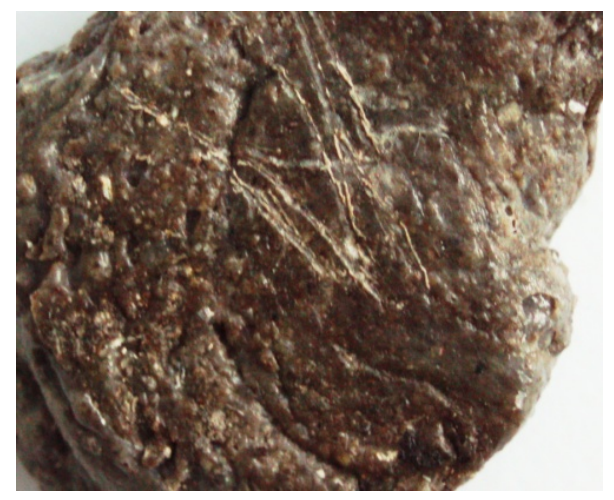

b)

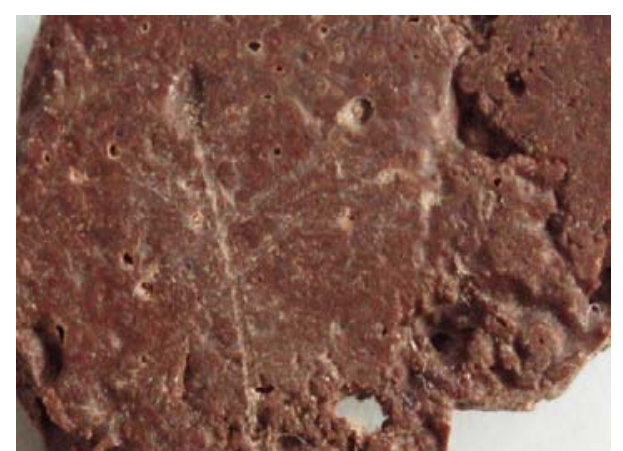

Fig. 5. Composite from mixture „Clay +PET”. 50\% (mass), a-white clay, b- brown clay

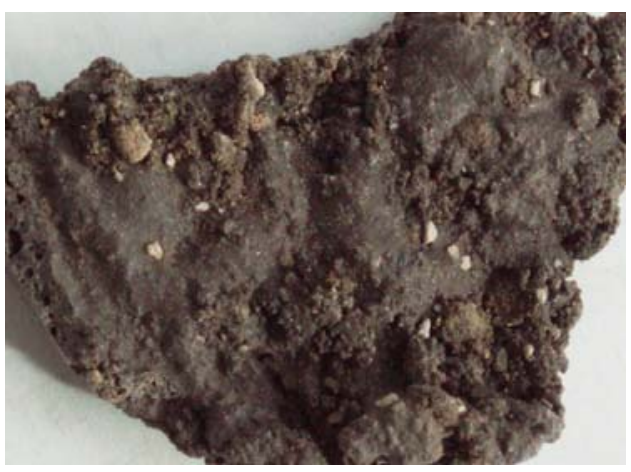

Fig . 6. Composite from mixture „Ash+ PET”(volume of ash 50\%)

And only by reducing the ash in the sample to 30 $20 \%$ (mass) was achieved a complete mixing of the components and monolythical structure developed (Fig.7).

The properties of best composites examples are shown in table 2.

Since the determinant in formation this type of composite is a specific free surface of mineral component, the amount of components in our experiments were converted into units of volume according to their density. PET density is of

$1.38 \mathrm{~g} / \mathrm{cm}^{3}$, ash $-1.82 \mathrm{~g} / \mathrm{cm}^{3}$. Test sample was prepared by mixing $2.06 \mathrm{~g}$ PET and $2.02 \mathrm{~g}$ ash (about $50: 50$ mass). That is $42 \%\left(1.1 \mathrm{~cm}^{3}\right)$ ash and $58 \%$ $\left(2.6 \mathrm{~cm}^{3}\right)$ PET in a volume.

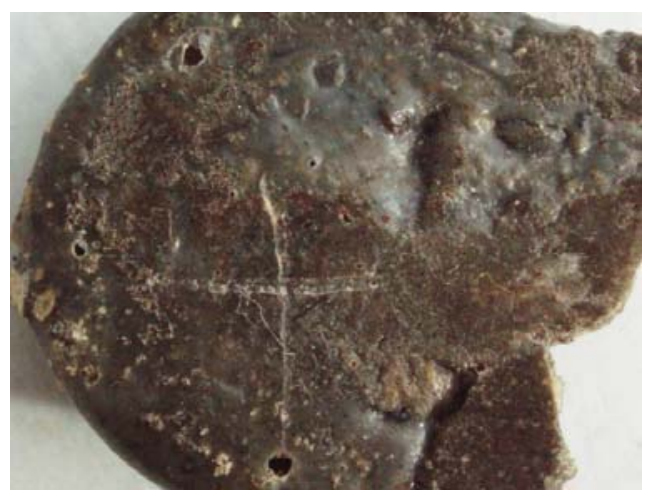

Fig 7. Composite from mixture „Ash+ PET”(volume of ash $22 \%$ )

TABLE2

PROPERTIES OF COMPOSITES

\begin{tabular}{|c|l|l|l|}
\hline $\mathrm{N}$ & Properties & Clay +PET & Ash+PET \\
\hline 1 & Density, $\mathrm{g} / \mathrm{cm}^{3}$ & $\begin{array}{l}1.70 \text { (white) } \\
1.77(\text { brown })\end{array}$ & $1.59-1.44$ \\
\hline 2. & Adhesion work, $\mathrm{mJ} / \mathrm{m}^{2}$ & $162.5-168.8$ & $59.3-60.1$ \\
\hline 3. & $\begin{array}{l}\text { Specific surface energy, } \\
\mathrm{mJ} / \mathrm{m}^{2}\end{array}$ & $25.4-31.5$ & $3.9-4.7$ \\
\hline 4. & $\begin{array}{l}\text { Wettability(Water } \\
\text { adsorption }) \%\end{array}$ & $0.5-1.3$ & $1.05-2$ \\
\hline
\end{tabular}

Since the investigated wood ash specific free surface [32] is $2.6 \mathrm{~m}^{2} / \mathrm{g}$ (average) total free surface of sample ash constitutes $5.25 \mathrm{~m}^{2}$. According to [20], the interfacial layer thickness is of 0.01-5 $\mu \mathrm{m}$. Calculations show that if the interfacial layer have minimum thickness of $0.01 \mu \mathrm{m}, 1.5 \mathrm{~cm}^{3}$ of the polymer may cover only $1.5 \mathrm{~m}^{2}$ surface of the ash. This means that the creating effective homogeneous and strong composite require plastic volume of 5.25 $\mathrm{cm}^{3}$, or $83 \%$ of the total composite volume. Accordingly, the amount of ash $22 \%$.

Our experiments approved that the best composite samples were obtained in this proportion (see Fig.7).

Analyzed composite "Clay+PET" samples showed that in the composite formation large role is playing adsorption capacity of the mineral part. Rough clay adsorption capacity of at least $15 \mathrm{mg} / \mathrm{g}$ (after methylene blue test), more than 30 times the ash adsorption ability $0.4 \mathrm{mg} / \mathrm{g}$. As a result, for example, fusing a sample of PET and clay ratio by volume of 43.7:56.3 was obtained a homogeneous solid monolith (see Fig 5). Calculations show that in spite of the large clay specific free surface of

$18 \mathrm{~m}^{2} / \mathrm{g}[37,38]$ it was enough the $2.17 \mathrm{~cm}^{3}$ PET to coat $1.68 \mathrm{~cm}^{3}$ clay. This means that the adsorptive 
layer thickness of the contact between the phases constitute $0.026 \mu \mathrm{m}$. According adsorption thermodynamics best adhesion system forming conditions is when adhesive surface energy is less than the surface energy of the substrate [22].

In our case, the clay $\gamma$ of at least $150 \mathrm{~mJ} / \mathrm{m}^{2}$, but PET only $44 \mathrm{~mJ} / \mathrm{m}^{2}$, what also provides better performance composite "Clay+PET." Tested composite combines the brittle components - clay or ash - and elastic plastic PET matrix. Since in our case the clay confinement tensile strength is much less than PET, in the first place tensile strength stresses tear inclusion, but further crack propagation is blocked in the plastic matrix. The critical fracture stresses according to Griffiths - Orovan-Irvine equation, in the case when the crack formation occurs at the plastic deformation zone increase of the surface energy of plastic deformation $\gamma_{p \text { : }}$

$$
\sigma=\sqrt{ } 2 E\left(\gamma_{s}+\gamma_{p l}\right) / \pi
$$

Where $E$ - plastic matrix Young's modulus, $c$ - critical crack length. It is known that plastic deformation surface specific energy of approximately $10^{3} \gamma_{s}$. Since for the homogeneous matter:

$$
\sigma=\sqrt{ } 2 E \gamma_{s} / \pi c,
$$

composite tensile strength theoretically can be increased to 30 times compared to the confinement strength.

$$
\sigma_{\text {comp }} / \sigma_{2}=\sqrt{ }\left(\gamma_{\mathrm{s}}+\gamma_{\mathrm{pl}}\right) / \gamma_{\mathrm{s}} .
$$

This means that the composite „Clay+PET” tensile strength may reach $36 \mathrm{MPa}$.

Approximately such results $(50-75 \mathrm{MPa})$ were achieved in industrial experiments of production composite of plastic and mineral waste [39].

But this is a case where the confinement ties with matrix components are ideal and elastic properties are not very different. But as inclusions in the matrix is a structural heterogeneity applying a load to composite in contact with the inclusions forms stress concentration, which depends on the confinement size, shape, its distribution in the matrix, the flexibility characteristics and type of links between them. So here is high importance of strong bonds between the inclusions and matrix, their quality and completeness. In the absence of adhesion any inclusion reduces the strength - especially tensile strength - inclusion do not perceive stresses and therefore it can be approximated as a crack or pores in composite. Our experiments found that the quality of those links in composite „Ash+PET" is lower than when the inclusions consists of clay particles. It means, that in order to obtain high quality composite material from mixture „Ash+PET” is necessity for additional procedures, such as ash adhesion capacity maximizing by adding modifiers, plasticizers, treatment with surfactants or temperature [40]. Thus, for example, is a patented technology of composite creation where in the composition of thermoplastic and ash is added bridging agent - salune grafted polyethylene or grafted alpha olefic copolymer - substances that interact at the same time with thermoplastics as well as with the ashes [41].

\section{CONCLUSIONS}

1. Theoretically and experimentally founded in principle feasibility to produce composite material of thermoplastic waste (PET bottles) combined with mineral waste (ash, clay, debris), which can be used in different areas - civil engineering, hardware and various parts production.

2. Composite creation technology is thermophysical based on plastic melting with mineral waste.

3. Determinants of creation homogeneous and mechanically durable composite are the specific surface energy, adsorption and adhesion characteristics of the components, the degree of dispersion, the content ratio of components and thermal exposure modes.

4. The experimentally determined the optimum conditions for the creation of composite. Clay and PET thermoplastic polymer composite component ratio is 50:50, ash and PET accordingly 20:80, the operating temperature of 300 to $320{ }^{0} \mathrm{C}$, the heating time of $20 \mathrm{~min}$.

5. Better quality composite formed of PET alloy with clay. Ash and PET composite quality may be improved by reduction PET viscosity and raising components mutual adhesion ability and the increasing contact surface specific energy.

\section{$\mathrm{V}$ REFERENCES}

[1] Inorganic waste. [Online] Available: http://www.owp.csus. edu/glossary/inorganicwaste.php. [Accessed May 5, 2015].

[2] G.Noviks, "Basis of optimal mineral inorganic wasteprocessing methods", in Environment. Technology. Resources: Proceedings of the 6-th International Scientific and practical conference, June 20-22, 2007.Rezekne, pp. 87101. Karen A.Hudson-Edwards and Bernhard Dold,"Mine waste Characterization, Management and Remediation", Minerals, 2015,5 pp. 82-85.

[3] "Waste generation and treatment". [Online]. Available: http://ec.europa.eu/eurostat/data/database [Accessed May $5,2015]$.

[4] D. Hoornweg and P. Bhada-Tata, What a waste. A global review of solid waste management. March 2012, No. 15. Urban development series - knowledge papers. Chapter 5. pp. 32-37. [Online]. Available: siteresources.worldbank.org/ INTURBANDEVELOPMENT/[Accessed May 5,2015].

[5] Y.Kim, J. Lee, Min Sun Yeom, Jae Won Shin, Hyungjun Kim, Yi Cui, Jeffrey W Kysar, James Hone, Yousung Jung and Seokwoo Jeon, "Strengthening effect of single-atomic-layer graphene in metal-graphene nanolayered composites", Nature Communications 07/2013;4:2114.DOI:10.1038/ncomms3114, pp.1-7.[Online].Available: http://www.researchgate.net/ publication/244991748. [Accessed March 7, 2015].

[6] Krishan K. Chawla, Composite Materials: Science and Engineering (Materials Research and Engineering), Springer, 2013.

[7] Autar K. Kaw, Mechanics of Composite Materials (2nd ed.). CRC Taylor \& Francis Group, 2005.

[8] В.Ржевский. Г.Я.Новик, Основы физики горных пород ,М.ЛЕНАНД, 2014. 
[9] Kim Christensen, Percolation Theory, London, 2002.

[10] D. Austin. Percolation: Slipping through the Cracks. [Online].Available:http://www.ams.org/samplings/featurecolumn/fcarc-percolation\#sthash.ulasL7vp.dpuf [Accessed March 12,2015]

[11] Daniel Genin, Percolation: Theory and Applications. NIST,2007.[Online]. Available: http:/www.pdfdrive.net/ percolation-theory-and-applicationse4996426.html [Accessed April 04,2015]

[12] “Теория перколяции”. [Online]. Available: http://worldof materials.ru/spravochnik/composites/40-teoriya-perkolyatsii [Accessed May 04, 2015].

[13] John C. Wierman "Critical Percolation Probabilities", NorthHolland Mathematics Studies, Volume 118, 1985, pp. 349359.

[14] Dietrich Stauffer, Ammon Aharony, Introduction in percolation theory, CRC Press, 1994.

[15] Tuck C.Choy, Effective Medium Theory: Principles and Applications, Oxford University Press, 1999.

[16] Landauer, Rolf. "Electrical conductivity in inhomogeneous media", in AIP Conference Proceedings, 40 American Institute of Physics. April 1978, pp. 2-45. doi:10.1063/1.31150.

[17] В.И.Оделевский, "Расчет обобщенной проводимости гетерогенных систем. Матричные двухфазные системы с невытянутыми включениями", Журнал Технической Физики, 1951. Т. 21Б, № 6. с. 667-677.

[18] Г.Я.Новик , М.Г.Зильбершмидт, Управление физическими свойствами пород в процессах горного производства, М.ЛКИ, 2010.

[19] A.Baldan,"Adhesion phenomena in bonded joints", Turkey International Journal of Adhesion \& Adhesives 38, 2012, pp 95-116.

[20] А.В.Гордеев, Моделирование свойств композищионных материалов, дисперсно армированных жесткими короткими волокнами , 2010, 124c.

[21] А.А.Берлин.В.Е.Васин, Основы адгезии полимеров,М., Химия, 1974.

[22] Hong T. Hahn and Stephen W. Tsai, Introduction to Composite Materials - Technology \& Engineering. CRC Press, 1980.

[23] M.Zenkiewicz, „Methods for the calculation of surface free energy of solids", Journal of Achievements in Materials and Manufacturing Engineering, Vol.24, Issue 1, September 2007 , pp.137-145.

[24] Г.И.Петрова. Э.Я.Бейдер, „Конструкционные материаль на основе армированных термопластов”, Российский химический журнал т.LIV,\#1, 2010.c.1-16. [Online]. Available: http://www.viam.ru/public Accessed March 20, 2015.

[25] Byung-Wan Jo, Seung-Kook Park, Jong-Chil Park „Mechanical properties of polymer concrete made with recycled PET and recycled concrete aggregates", Construction and Building Materials 22, 2008.pp. 2281-2291.
[26] Yun-Wang Choi, Dae-Joong Moon, Jee-Seung Chung, SunKyu Cho „Effects of waste PET bottles aggregate on the properties of concrete", Cement and Concrete Research 35 2005, pp.776-781.

[27] F. M. Fowkes," Attractive Forces at Interfaces", in: Industrial and Engineering Chemistry 56, 12 (1964), P. 40-52.

[28] A.W. Neumann, Applied Surface Thermodynamics ,CRCPress2014[ebook],Available:https:/www.crcpress.com/p roduct/isbn/9780849396878

[29] "Common Waste and Materials" [Online]. Available: http://www.epa.gov/osw/conserve/materials/plastics.htm [Accessed March10, 2015].

[30] Adrian K. James,Ronald W.Thring, Steve Helle and Harpuneet S.Ghuman. "Ash management rewiev- application of Biomass Bottom Ash", in Energies, 5, 2012, pp. 38563873.

[31] G.Noviks," Investigation of Biomass Ash Properties for their Utilization Assessment" in Environment. Technology .Resources. Proceedings of the 9-th International Scientific and practical conference, June 20-22, 2013.Rezekne, pp. 168174.

[32] "PET (polyethylene terephalate)" [Online]. Available: http://www.plastic-products.com/part12.htm [Accessed March15,2015]

[33] N. Torres, J.J. Robin , B. Boutevin.“ Study of thermal and mechanical properties of virgin and recycled poly(ethylene terephthalate) before and after injection molding " in European Polymer Journal Volume 36, Issue 10, 1 , 2000, pp. 2075-2080

[34] "Surface Energy Data for PET: Poly(ethylene terephthalate)".[Online].Available:www.accudynetest.com/pol ymer surface data/pet.pdf [Accessed March,24]

[35] R. C. Mielenz , M.E.King Physical-Chemical Properties and Engineering Performance of Clays. www.clays.org/journal/ archive/volume\%201/1-1-196.pdf

[36] Bronislaw Janczuk, Tomasz Bialo Piotrowicz, "Components of Surface Free Energy of some Clay Minerals" in Clays and Clay Minerals, Vol. 36, No. 3, 1.988, pp 243-248.

[37] E. Chibowski, P. Staszczuk. Determination of Surface Free Energy of Kaolinite, in Clays and Clay Minerals, Vol. 36, No. 5, 455--461, 1988.

[38] “Технология производства композиционных материалов на основе П ЭТ, переработка отходов”. [Online]. Available: http://www.ecoteco.ru/?id=140 [Accessed March20, 2015].

[39] Chi- An Dai, Tai-An Tsui, Yao-Yi Cheng, "Adhesion of PET/PSMA Interfaces Reinforced with Plasma Treatment "in Surface review and Letters, Vol.13, No2\&3, 2006, World Scientific Publishing Company, pp 265-271.

[40] Maziyar Bolourchi, Roger W. Coupled fly ash filled polymer compounds. Patent WO 2013082047 A1 Nun 6, 2013 Nov 27 2012 Nov 29, 2011. 